\title{
JOB (IN)STABILITY IN THE EUROPEAN LONG-TERM CARE WORKFORCE
}

\author{
Stefano Visintin \\ Marta Elvira
}

Carlos Rodríguez Lluesma 


\title{
JOB (IN)STABILITY IN THE EUROPEAN LONG-TERM CARE WORKFORCE
}

\author{
Stefano Visintin ${ }^{1}$ \\ Marta Elvira ${ }^{2}$ \\ Carlos Rodríguez Lluesma ${ }^{3}$
}

\begin{abstract}
Demographic changes and growing demand are making Long-Term Care (LTC) services for chronic patients and senior citizens a dynamic sector facing major challenges. Jobs in this sector tend to have limited attractiveness, to be associated with low retention rates and, consequently, potential workforce shortages. The objective of the present paper is to measure LTC job stability in order to quantify a potential attractiveness gap between caregiver occupations and other related careers across European countries. We make use of the European Labour Force Survey database (EU-LFS). The data covers 26 countries over the period 19922011. We estimate the conditional continuation probabilities of maintaining a current job over time for LTC workers, applying a retention rates approach. We compare these estimates to those for typical health sector workers within and across various countries. Our findings indicate that, although LTC jobs are as stable as other healthcare related occupations in most of Europe, two groups of countries exhibit different patterns. In Southern and Eastern European countries, LTC occupations appear less stable. Central European states, by contrast, reveal an apparently higher retention in favor of LTC occupations.
\end{abstract}

JEL Classification: I12, J63

Keywords: Long-term care, LTC occupations, Job stability, Retention rates.

\footnotetext{
${ }^{1}$ Research Assistant, IESE.

${ }^{2}$ Professor, Strategic Management, IESE.

${ }^{3}$ Professor, Managing People in Organizations, IESE.
} 


\section{JOB (IN)STABILITY IN THE EUROPEAN LONG-TERM CARE WORKFORCE}

\section{Introduction}

\section{Long-Term Care: Relevance and Reasons for Concern}

Demographic changes, growing demand for higher quality healthcare and social transformations are making Long-Term Care (LTC) one of the most dynamic sectors in advanced economies (European Commission, 2008 and 2012; OECD, 2011a, Ochsner et al, 2009). LTC services consist of those activities implemented in order to make a dependent person's quality of life as high as possible, according to individual preferences. Dependent persons are those with chronic illness or disabilities who are not able to care for themselves. Since the probability of suffering from chronic disease increases with age, care needs typically increase for senior citizens. LTC services are often classified into medical and non-medical. The latter category consists of assisting with the person's activities of daily living (e.g. eating, dressing or bathing). Care services are often provided informally, mainly by relatives or members of the recipient's social network. Professional services are provided according to the level of dependency and can take place at home, in the community or in institutions such as nursing homes or skilled nursing facilities. This paper focuses on the workforce that provides professional LTC services.

According to the European Commission estimates, LTC services are expected to increase their weight within the European Union GDP from 1.8\% to 3.4\% between 2010 and 2060 (European Commission, 2012). ${ }^{1}$ This growth raises two notable challenges: fiscal sustainability and a higher workforce demand. The former is a recurring headline in policy makers' agendas, while the second has received limited attention. Little is known about the potential worker shortage

\footnotetext{
${ }^{1}$ For illustration purposes, the Bureau of Labor Statistics (2012) estimates that over 700,000 jobs as "home health aides" and 600,000 as "personal care aides" will be created in the United States by 2020. These figures represent a $69 \%$ and $70 \%$ increase over values reported in 2010, respectively.
} 
affecting the sector (Dowson and Surpin, 2000; Fujisawa and Colombo, 2009; European Commission, 2008; OECD, 2009), but the consequences might be dire, including poor care quality, unsatisfactory physical conditions for assisted persons (Castle and Engborg, 2005) and higher recruiting costs for the firms and institutions operating in the sector (Seavey, 2004; Fujisawa and Colombo, 2009).

Workforce shortages could derive from the mismatch between caregiver demand and supply. From the demand perspective, since LTC consists of personal attention and is therefore labor intensive, an increased demand for services is likely to increase the need for workers in the sector substantially. From the supply side, care giving may not be perceived as an attractive field: care work means physically and mentally taxing tasks and challenging work shifts/schedules. Moreover, when formal contracts do exist for these workers, they are often precarious and with low compensation. These job characteristics are predictors of dissatisfaction (Delp et al., 2010) and might partly account for the high quit rates and short employment spells, i.e., the low job stability often observed in the sector (see Castle and Engberg, 2005; Hussein et al., 2010; Olson, 2010). Low job stability means short job duration expectations. And these, in turn, might translate into lower skill development, low wage increases through tenure and limited access to employer-based benefits (e.g., pension plans or training). In short, low job stability and low job attractiveness and quality come together.

In sum, job stability becomes a central dimension in researching possible sources of work shortages. In order to prepare for the challenges the LTC sector faces due to the expected increase in demand, it is essential to understand the supply mechanism and to quantify job stability in the sector. Detailing this information should serve all actors involved well, from final users of care to service providers as well as policy makers and taxpayers. In this paper, we focus on job stability in the LTC sector. In particular, using European Labour Survey data we examine the extent to which employment duration differs between LTC workers and that of similar occupations in several European countries during the twenty-year period from 1992 to 2011.

\section{Research Gaps}

A critical question to address is to what extent LTC jobs are more or less attractive than other comparable occupations in Europe. This question is especially relevant in a comparative perspective, given that different countries experience workforce shortages differently. Countries provide LTC services under different frameworks, in terms of provision, organization and financing, so that low work attractiveness could be related to specific frameworks. Although most European countries face similar demographic challenges and growing demand for LTC, the solutions proposed to finance and deliver LTC services vary consistently across countries (Riedel and Kraus, 2011; Nadash at al., 2012). For example, the proportion of public and private funding or the share of formal vs. informal care can vary widely; some countries have introduced homebased care programs, others mainly support care in assisted living facilities or nursing homes (OECD, 2011). ${ }^{2}$ Cross-country comparisons in the resulting workforce structure should illuminate the organization of LTC service delivery and possibly help inform policy decisions.

\footnotetext{
${ }^{2}$ Krauss et al. (2010) provide a typology of the LTC systems in Europe based on four important dimensions: public expenditure, private expenditure, intensity of use of LTC services and support to informal caregivers. They eventually classify European countries into four clusters.
} 
Landmark studies in this field are challenged by the scarcity of comparable data allowing for cross-country comparison and/or including long-term information, which makes figures and labor market dynamics in the sector harder to understand. For example, institutional research relies on macro-focused databases whose main aim is the description of the whole Health Services industry (OECD, 2011a, 2011b; Fujisawa and Colombo, 2009, European Commission, 2008, 2012). These studies lack precise data on LTC workforce characteristics, such as job stability, and on comparisons between LTC and related occupations, such as health care staff.

Studies that address questions related to LTC work stability are often country-specific, such as the National Clearinghouse on the Direct Care Workforce (2006), Harrington et al. (2009) or Baughman and Smith (2011) for the United States; Hussein et al. (2011) and Hussein (2011) for the United Kingdom; Rodriguez Sampayo et al. (2011) for Spain; Hackmann (2009) and Mennicken et al. (2013) for Germany. Other relevant publications rely on establishment-level or local economic data, often obtained from case studies or surveys, see Castle et al. (2006 and 2007), Delp et al. (2010) or Hussein et al. (2011). These country- (or case-) specific studies offer important insights, but their outcomes are hardly comparable and are limited in their international validity. A notion common to several of these studies is that LTC occupations present low job stability and low attractiveness for workers. Nevertheless, the literature fails to provide empirical measures of job stability and to offer an international comparison that takes different LTC provision systems into consideration.

In this paper, we aim to ascertain whether low job stability indeed characterizes LTC occupations. We examine the LTC labor force job possibilities and compare them with those of the Human Health and Social Work Activities workforce in 26 European countries over the last twenty years. ${ }^{3}$ Using current data and a widely accepted methodology that permits international comparisons, we measure and compare LTC job stability with that of other related professions. Our primary objective is to describe job stability in the sector in terms of job tenure and job continuation across different European Union countries, organizing the data in order to allow for within and cross-country comparisons over time. Measuring job stability has two implications: it allows for distinguishing between provision schemes (at country level) and for creating solid measures that can be used in further empirical investigations on the factors affecting job stability in the sector. Our results indicate that even though LTC jobs are as stable as other health care related employments in most of Europe, the patterns differ between two groups of countries. In Southern and Eastern European countries, LTC occupations are noticeably less stable in terms of employment spells and one-year retention rates relative to those of Central European countries.

The next section briefly describes the dataset we use, the European Union Labour Force Survey (EU-LFS), and the method implemented to identify health care and LTC workers. Section 3 explains the empirical methodology. Finally, we detail the observed evolution of job stability in the health and LTC sectors in Europe built upon data from 1992 to 2011.

3 The definition of Human Health and Social Work Activities corresponds to Section Q of the Statistical Classification of economic activities in the European Community NACE Rev.2. See the following section in this manuscript for further details. 


\section{Data and Empirical Strategy}

The European Union Labour Force Survey is a large rotating, random sample survey representing the population in private households in 30 European countries. ${ }^{4}$ The national statistical institutes are responsible for collecting the data, which are then centrally processed by Eurostat. Although data exists starting in 1983, availability for individual countries depends on their EU accession date. The EU-LFS provides quarterly and yearly variables concerning labor participation for individuals, ages 15 and over, as well as for those outside the labor force. EU-LFS variables include demographic background, labor status information and employment characteristics as well as job and unemployment tenure.

In this paper, we focus on job stability in the LTC sector. Building on individual data we create country-level indexes. In particular, we examine the extent to which employment duration differs between LTC workers and that of similar occupations in several European countries over the last 20 years.

Different empirical approaches to job stability exist. A common one consists of observing the average employment spell of employed individuals and their tenure distribution. These measures are sources of important information about the state of the labor force. However, the EU-LFS, like other similar surveys, is not designed to provide complete employment spells (the kind of data needed to observe average spells and distributions), but the time spent employed by each individual up to the reference week, i.e., the in-progress (or incomplete) employment duration. An average measure obtained from these spells would be the average of incomplete duration of employment. Since length and sampling biases might arise, this measure misrepresents the average complete duration of employment, so it would not be a reliable measure of job stability (for a thorough discussion on these issues, ref. Salant, 1977, and European Commission 2009, p. 80). ${ }^{5}$

Another approach to measuring job stability consists of computing the conditional continuation probability of employees, i.e., the probability that a job will continue for some specified period of time given a certain initial tenure. The conditional probability, or retention rate, is widely used and accepted to observe job stability patterns and their changes over time (Diebold et al., 1997; Neumark et al., 1999; Heinsz, 2005; and Brochu, 2011). As is common in this literature, we apply a synthetic cohort approach to estimate retention rates from consecutive crosssectional surveys of LTC workers and compare the results with a benchmark occupation category: health sector (total) workers. ${ }^{6}$ The aim is to calculate the probability that a worker will remain in his or her present occupation over time. When one-year retention rates are computed for one sector in one country, we obtain an estimation of the percentage of workers (of the sector in that country) that will hold the same position after one year. We can compute

\footnotetext{
${ }^{4}$ EU-LFS is similar in content to the American Current Population Survey and the Canadian Labour Force Survey. The collection of job tenure information is implemented monthly in the EU-LFS and C-LFS, but only at irregular intervals of at least two years in the A-CPS. Thus, when it comes to studying job tenure, the EU-LFS and C-LFS are better suited than the A-CPS.

${ }^{5}$ Furthermore, this measure is difficult to interpret when the tenure distribution becomes more polarized and the shares of workers at the highest and lowest levels of stability simultaneously increase. This is the case of the present (crisis) situation in several countries.

${ }^{6}$ The category of health sector workers comprises all those occupations related with health and social care, from hospital personnel to social workers. See below for further details. These categories were selected because they are related to LTC occupations in terms of scope and personnel training.
} 
retention rates for workers with different tenure, e.g., workers in their first year of tenure, and then produce a weighted average referring to all workers employed in a sector in a given country each year. This method permits a comparison of the retention rates of two different workers' categories, in our case LTC and health sector employees, as well as observing how retention rates evolve as workers' tenure increases.

Here we denote the individual as $i$, tenure as $s$, time as $t$ and the category characteristics as $c$ (e.g. workers from a specific sector), where $X_{i t}$ is the vector of these characteristics and $T E N_{i t}$ is individual tenure. Following Brochu (2011) we derive the retention rate as

$$
R_{s t}^{c}=\frac{E\left(1\left[T E N_{i t}=s+1, X_{i t}=c\right]\right)}{E\left(1\left[T E N_{i t}=s, X_{i t}=c\right]\right)}
$$

being $1[$.$] an indicator function equal to 1$ when the conditions inside the brackets hold, and zero otherwise. For each category $c$, the retention rate can be estimated as the relation between the number of respondents reporting tenure of $s$ and $s+1$ in two repeated surveys. Therefore, if the sample size at time $t$ is $n_{t}$ the estimated retention rate is

$$
\hat{R}_{s t}^{c}=\frac{\sum_{i=1}^{n_{t+1}} 1\left[T E N_{i t}=s+1, X_{i t}=c\right] / n_{t+1}}{\sum_{i=1}^{n} 1\left[T E N_{i t}=s, X_{i t}=c\right] / n_{t}}
$$

The synthetic cohort appellation arises from the need to rely on population cohorts to "follow" the same category of workers over time. In order to estimate retention rates according to (2), data from two repeated surveys is needed. However, EU-LFS data does not follow individuals across different surveys. To avoid this shortcoming and to exploit information from two consecutive surveys, the computation is based on two cohorts representing individuals from the same job entry group, the synthetic cohort. The estimation is computed by following the experience of a synthetic cohort forward through time; in other words, the retention rate for year $t$ is estimated using present and future data (data from the year $t$ and the year $t+1$ ). The resulting retention rate can therefore be considered a "forward tracking" estimator. See Corack and Heisz(1996) for further discussion.

Given that the EU-LFS provides yearly values for employment spell lengths in months, retention rates could be performed for intervals as short as one month. However, as noted by Heisz (2005) "Shorter intervals of less than one year tended to be unstable, reflecting sampling error introduced into the process by the synthetic cohort approach." In the present analysis we compute up to 50 one-year retention rates. The limit of 50 was chosen since it is a figure well above the length of the average working lifespan and almost all samples of individuals are included within the 1-50 period. Specifically, according to data availability, we calculate the one-year retention rates for employees with tenure from 1 to 50 years. Once these rates have been computed for time $t$, a single average one-year retention rate can be calculated as the weighted average of the retention rates corresponding from 1 to 50 years of tenure:

$$
R_{1 t}=\sum_{i=1}^{50} \gamma_{i} R_{1 i t}
$$


where $\gamma_{i}$ corresponds to the proportion of individuals with tenure $i$ at time t. This weighted average of the retention rate can be interpreted as an estimation of the probability that a typical worker will maintain her present employment for 12 months or more from the beginning of period $t$, and represents a measure of job stability (for a sector in a country in a specific year). Sampling and tenure distribution polarization biases, the main shortcomings of the average incomplete employment spells, do not affect these estimated retention rates. An additional advantage of this approach is that it is suited to reflect economic events taking place over time (Heisz, 2005).

LTC services do not fall directly under existing standard classifications' distinctions of economic activities, such as the International Standard Industrial Classification of All Economic Activities (ISIC) or the Statistical Classification of Economic Activities in the European Community (NACE). Nor is there a direct correspondence with the LTC workforce and the standard job-occupation categories, e.g. the International Standard Classification of Occupations (ISCO). Indeed, the distribution of LTC workers across different ISCO and NACE varies within countries in response to socio-economic and policy changes as well as across countries, reflecting the differences in the organization of care for dependent persons (Fujisawa and Colombo, 2009; Simonazzi, 2009; Geerts, 2011).

In order to perform our analysis on the most reliable selection of LTC workers we crossed data corresponding to occupations and economic activities. The EU-LFS provides 3-digit level ISCO occupation codes and 1-digit level NACE codes for each currently working individual included in the survey. ${ }^{7}$ In this paper we defined an LTC worker as an employed individual whose job occupation is included in one of the following four ISCO-88 categories: 513, 323, 346 and 913. The first two consist of ISC0-88 513, which is defined as Personal care and related workers, and ISCO-88 323, Nursing and midwifery associated professionals. These group occupations cover a substantial number of LTC workers (Geert, 2011). Nevertheless, given the high variety of LTC occupations, several workers are not included within these definitions. Social work associated professionals (ISCO-88 346) and Domestic and related helpers, cleaners and launderers (ISCO-88 913) were therefore added. ${ }^{8}$ Since including all these occupation categories could lead to an overestimation of the weight of the workforce size, by including a non-LTC related workforce we tightened the selection criteria adding a filter for economic-activities. Among all workers reporting the previously cited occupation codes, we exclusively selected those whose economic activities corresponded to NACE Rev.1 codes: N, L and P. ${ }^{9}$ One further complication arises from the changes in occupation and economic activities' classification in data collection over time. Table 1 presents the correspondence in the codes' classification and the timing of their application.

\footnotetext{
${ }^{7}$ The economic activity of the local unit is collected under NACE rev. 1 from 1992 to 2007 and NACE rev.2 from 2008 onward. The occupation of the individual is collected under ISCO-88 from 1992 to 2010 and ISCO-08 from 2011 onward.

${ }^{8}$ According to the ILO correspondence tables, the ISCO-88 - ISCO-08 correspondences for these categories are: 513, 532; 323, 322; 346, 341; 913, 911.

9 NCAE rev. 2 code $Q$ is defined as Human health and social work activities; code 0 corresponds to Public administration and defense; compulsory social security and code T represents Activities of households as employers; undifferentiated goods- and services- producing activities of households for personal use.
} 


\section{Table 1}

LTC workers' related ISCO and NACE correspondence

\begin{tabular}{|c|c|c|c|}
\hline ISCO codes & ISCO-88 (1992-2010) & ISCO codes & ISCO-08 (2011) \\
\hline 513 & Personal care and related workers & 532 & Personal care workers in health services \\
\hline 323 & $\begin{array}{l}\text { Nursing and midwifery associated } \\
\text { professionals }\end{array}$ & 322 & Nursing and midwifery associated professionals \\
\hline 346 & Social work associated professionals & 341 & $\begin{array}{l}\text { Legal, social and religious associated } \\
\text { professionals }\end{array}$ \\
\hline 913 & $\begin{array}{l}\text { Domestic and related helpers, cleaners } \\
\text { and launderers }\end{array}$ & 911 & Domestic, hotel and office cleaners and helpers \\
\hline NACE codes & Rev.1 (1992-2007) & NACE codes & Rev.2 (2008-2011) \\
\hline $\mathrm{N}$ & Health and social work & $\mathrm{Q}$ & Human health and social work activities \\
\hline L & $\begin{array}{l}\text { Public administration and defense; } \\
\text { compulsory social security }\end{array}$ & $\mathrm{O}$ & Public administration and defense \\
\hline $\mathrm{P}$ & Activities of households & $\mathrm{T}$ & Activities of households as employers \\
\hline
\end{tabular}

Because we explore job stability patterns, it seems opportune to compare the LTC sector-specific indicators presented above with certain reference categories. Workers belonging to the health sector in general are meaningful benchmark categories for LTC. Retention rates for workers belonging to the NACE code H, Human and social work, are computed and used as a benchmark. ${ }^{10}$

A typical drawback of survey-based data is that many respondents use some form of "rounding" strategy for quantitative answers, resulting in heaped data with large shares of responses concentrating around sensible values. Self-reported employment spell lengths are no exception. Notable spikes in the distribution around "digit preferences" can be observed. In reporting their employment spells, respondents seem to prefer rounded digits (e.g. 10, 20 and so on) and complete-year corresponding month values (e.g. months 12, 24, 36 and so on). This bias requires correction to smooth raw data on duration prior to applying the methodology presented above. The choice of smoothing technique and weights in this sort of data is a source of debate in the existing demographic literature. Researching methodologies in this direction goes beyond the aims of the present paper. Therefore, we decided to apply a widely accepted smoothing technique, running means with a weight of 12 . The choice of the weight is motivated by the fact that we observe yearly data and compute yearly retention rates. The extracted data on the LTC workforce cover the period between 1992 and 2011 and are geographically spread over 26 countries of the European continent.

\section{Results}

\section{In-Progress Average Job Tenure}

Average employment durations of in-progress job spells for 26 European countries are detailed in Table 2. Three different time spans (1992-1999; 2000-2006; 2007-2011) are illustrated for tenures of LTC workers and the whole health sector workforce.

\footnotetext{
${ }^{10}$ NACE Rev.2 code Q Human health and social work activities is used from 2008 onward.
} 


\section{Table 2}

Average in-progress job tenure of the LTC and health sectors in Europe, in months

\begin{tabular}{|c|c|c|c|c|c|c|}
\hline & \multicolumn{2}{|c|}{ 1992-99 } & \multicolumn{2}{|c|}{$2000-06$} & \multicolumn{2}{|c|}{ 2007-11 } \\
\hline & LTC & Health & LTC & Health & LTC & Health \\
\hline Austria & & & 120 & 126 & 120 & 125 \\
\hline Belgium & 114 & 139 & 128 & 154 & 126 & 158 \\
\hline Switzerland & 93 & 97 & 102 & 105 & 106 & 110 \\
\hline Cyprus & 56 & 132 & 60 & 144 & 52 & 156 \\
\hline Czech Republic & & & 128 & 136 & 129 & 141 \\
\hline Germany & & & 108 & 114 & 119 & 125 \\
\hline Denmark & 83 & 89 & 81 & 85 & 102 & 108 \\
\hline Estonia & 121 & 132 & 120 & 131 & 127 & 134 \\
\hline Spain & 91 & 130 & 101 & 147 & 103 & 159 \\
\hline Finland & 115 & 125 & 115 & 125 & 120 & 130 \\
\hline France & 119 & 136 & 119 & 136 & 137 & 150 \\
\hline Greece & 107 & 132 & 107 & 132 & 107 & 132 \\
\hline Hungary & 111 & 135 & 123 & 145 & 111 & 135 \\
\hline Ireland & 132 & 116 & 85 & 113 & 99 & 118 \\
\hline Iceland & & & 75 & 93 & 103 & 111 \\
\hline Italy & 137 & 152 & 132 & 165 & 108 & 173 \\
\hline Lithuania & & & 121 & 168 & 120 & 162 \\
\hline Luxemburg & 104 & 115 & 116 & 125 & 124 & 132 \\
\hline Latvia & & & 136 & 145 & 150 & 162 \\
\hline Netherlands & 98 & 106 & 111 & 119 & 117 & 125 \\
\hline Norway & & & & & 115 & 118 \\
\hline Portugal & 140 & 155 & 130 & 150 & 143 & 155 \\
\hline Romania & & & 107 & 141 & 108 & 145 \\
\hline Sweden & 148 & 145 & 145 & 154 & 140 & 149 \\
\hline Slovakia & & & 133 & 156 & 134 & 156 \\
\hline United Kingdom & 82 & 97 & 95 & 103 & 100 & 110 \\
\hline
\end{tabular}


Note that the average in-progress tenure in the LTC sector is shorter than that of the average in-progress spell of the generic health sector worker in all but two cases. ${ }^{11}$ In most countries (18 of 26), LTC spells are slightly shorter than health sector spells (from 3\% to 15\%), while only in five cases they are 20\% or higher, and shorter (Cyprus, Spain, Italy, Lithuania, Romania ). Countries where the tenure gap is narrowest are Austria, Germany, Norway and Sweden. Geographical patterns seem to emerge: while the difference in average job tenure is narrow in central and northern countries, while broader gaps are observed in Southern and Eastern European countries. Since countries respond with different provision frameworks to the LTC service's needs, these sorts of outcomes suggest that country specific idiosyncrasies might have an influence on the observed workers' job duration.

Average in-progress tenure might be an imperfect indicator of job stability, since sampling and length biases might have different effects in the LTC and health sectors. If we consider that LTC holds a higher portion of recently created jobs, average spells might consistently underestimate LTC spells with respect to the health sector. ${ }^{12}$ In order to understand in which countries LTC is actually a more or less stable occupation than the typical health occupation, we next conduct retention rates analyses.

\section{Retention Rates}

The one-year retention rate indicates the probability that a typical worker will remain in his or her present employment over 12 months, which depends on both the probability of being dismissed and the probability of quitting the present job. A comparison of retention rates, contrasting different economic sectors within the same framework (e.g., a country where jobrelated regulations are the same for all sectors), should speak to differences in micro-relations between sectors. Differences in wages, working hours, shifts, training programs and other contract conditions can be at the base of retention rates' differentials. As discussed in Section 1.2, high job stability in the long run can be associated with high(er) quality jobs (for example, in terms of wage, hours and duration), while low job stability might be related with low job quality (Heisz, 2005). Comparing the job stability of LTC workers with that of the typical health care workforce we aim to obtain a measurement of the relative attractiveness of the former occupations with respect to related ones. More stable jobs, with low separation rates and, therefore, higher retention rates, can result from more desirable working conditions. Thus, the differential in retention rates between sectors represents a measure of the job-quality variance between these activities, among other things.

\footnotetext{
${ }^{11}$ Ireland and Sweden for the period 1992-1999.

12 Following Salant (1977) and the European Commission (2009, p. 80), the length bias arises here with different magnitudes, underestimating to a greater extent the length of the sector with the fastest recent expansion.
} 


\section{Table 3}

Average one-year retention rates, LTC and health sector, 26 European countries, 1992-2010 averages

\begin{tabular}{lccc}
\hline & LTC & Health & Ratio (LTC/H) \\
\hline Austria (at) & 0.95 & 0.95 & 1.00 \\
Belgium (be) & 0.97 & 0.95 & 1.03 \\
Cyprus (cy) & 0.76 & 0.93 & 0.82 \\
Czech Republic (cz) & 0.95 & 0.95 & 0.99 \\
Denmark (dk) & 0.90 & 0.89 & 1.01 \\
Estonia (ee) & 0.92 & 0.92 & 1.00 \\
Finland (fi) & 0.93 & 0.92 & 1.01 \\
France (fr) & 0.92 & 0.93 & 0.99 \\
Germany (de) & 0.98 & 0.96 & 1.02 \\
Greece (gr) & 0.91 & 0.94 & 0.97 \\
Hungary (hu) & 0.95 & 0.93 & 1.01 \\
Ireland (ie) & 0.97 & 0.95 & 1.02 \\
Island (is) & 0.91 & 0.92 & 1.01 \\
Italy (it) & 0.95 & 0.97 & 0.98 \\
Latvia (Iv) & 0.95 & 0.93 & 1.02 \\
Lithuania (It) & 0.92 & 0.94 & 0.96 \\
Luxemburg (lu) & 0.96 & 0.95 & 1.01 \\
Netherland (nl) & 0.99 & 0.96 & 1.03 \\
Norway (no) & 0.94 & 0.94 & 1.00 \\
Portugal (pt) & 0.94 & 0.93 & 1.01 \\
Romania (ro) & 0.91 & 0.94 & 0.96 \\
Slovakia (sk) & 0.93 & 0.95 & 0.98 \\
Spain (es) & 0.86 & 0.92 & 0.94 \\
Sweden (se) & 0.96 & 0.96 & 1.00 \\
Switzerland (ch) & 0.96 & 0.91 & 1.05 \\
United Kingdom (uk) & 0.90 & 0.90 & 1.00 \\
\hline & & &
\end{tabular}

Retention rates presented in Table 3 suggest, first, that country idiosyncrasies matter when comparing LTC job stability. The probability of maintaining the current job for one additional year ranges from 99\% (the Netherlands) to 76\% (Cyprus). Again, the Southern and Eastern European countries show the lowest absolute retention levels. Most interesting is the comparison between the LTC and health sectors within the countries themselves. In most countries, LTC jobs are as stable as health care jobs. In half of the 26 countries included in the analysis, LTC and health care retention rate differences are lower than two percentage points. ${ }^{13}$ This outcome suggests that in a large portion of Europe LTC jobs are as stable as other similar occupations. ${ }^{14}$ Nevertheless, in seven countries, LTC retention rates are clearly lower than those in health care, indicating a lower stability. Note also that in six countries LTC jobs appear more stable than those in health care.

\footnotetext{
${ }^{13}$ We consider the 0.98 and 1.02 boundaries in the calculation of the LTC/H retention rate ratios.

14 Austria, Czech Republic, Denmark, Estonia, Finland, France, Hungary, Island, Luxemburg, Norway, Portugal, Sweden, United Kingdom.
} 
The geographical pattern suggests that countries where LTC job stability is lower are all in Southern or Eastern Europe, namely Cyprus, Greece, Italy, Spain, Lithuania, Romania and Slovakia. By contrast, countries where LTC job stability is higher than the benchmark sector are all central European states: Belgium, Switzerland, Germany, the Netherlands, Ireland and Latvia.

Cross-country differences appear clear in Figure 1, which presents the evolution of the (oneyear) retention rates for LTC and the health sector in the five largest European economies. As might be expected, retention rates are low during the first period of tenure and grow as time spent with the same employer increases, since layoffs and voluntary separations are both more frequent during the first years of tenure. The increase in retention is rapid in all countries during the first five years of tenure and it decidedly slows down from then on. ${ }^{15}$ In absolute terms, retention rates present consistent cross-country differences. France, Italy and Germany show conditional continuation probability above 94\%, while Spain and the United Kingdom are examples of more dynamic job markets where retention averages around 90\%. ${ }^{16}$

Beyond cross-country differences, Figure 1 confirms that in some cases LTC retention rates are lower (Italy and Spain), close to (France and the United Kingdom) and higher (Germany) than the health care sector's benchmark. The average difference varies between $-4 \%$ (Spain) and $+2.5 \%$ (Germany).

\footnotetext{
${ }^{15}$ A spike corresponding to year three of tenure can be observed and is due to a consistent heap in data reporting that affects all countries and cannot be cleaned out by the smoothing technique applied without the loss of relevant information.

${ }^{16}$ The former is due to very low retention rates during the first five years of tenure; the latter is due to constant low retention rates.
} 


\section{Figure 1}

One-year retention rates in the largest European economies
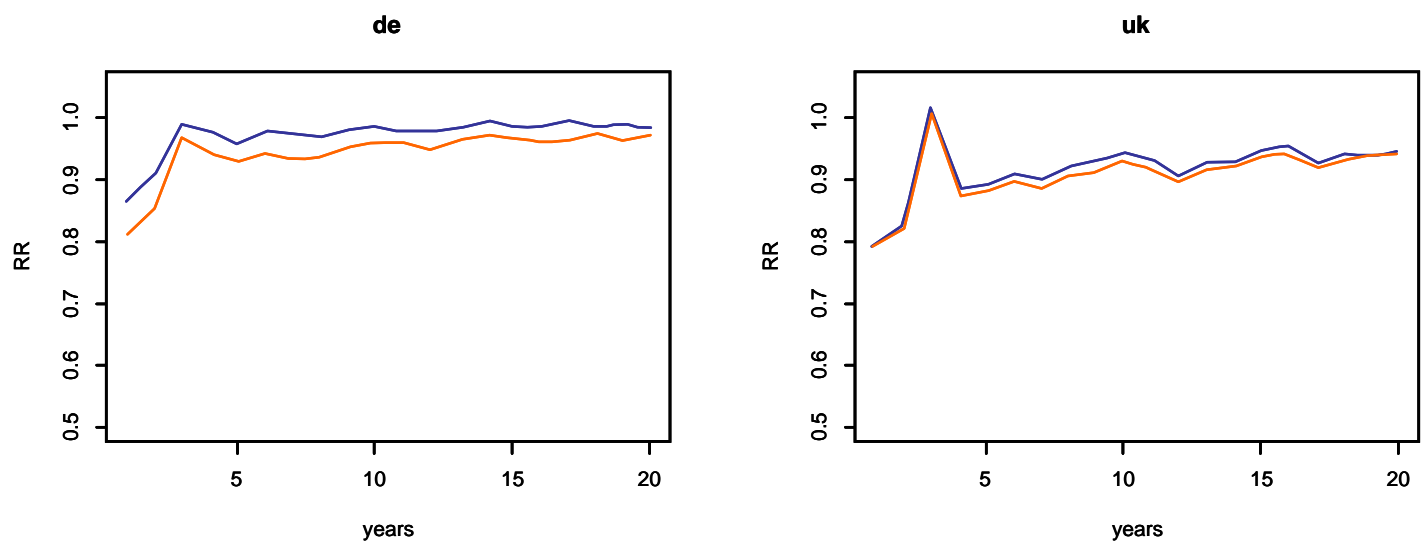

fr
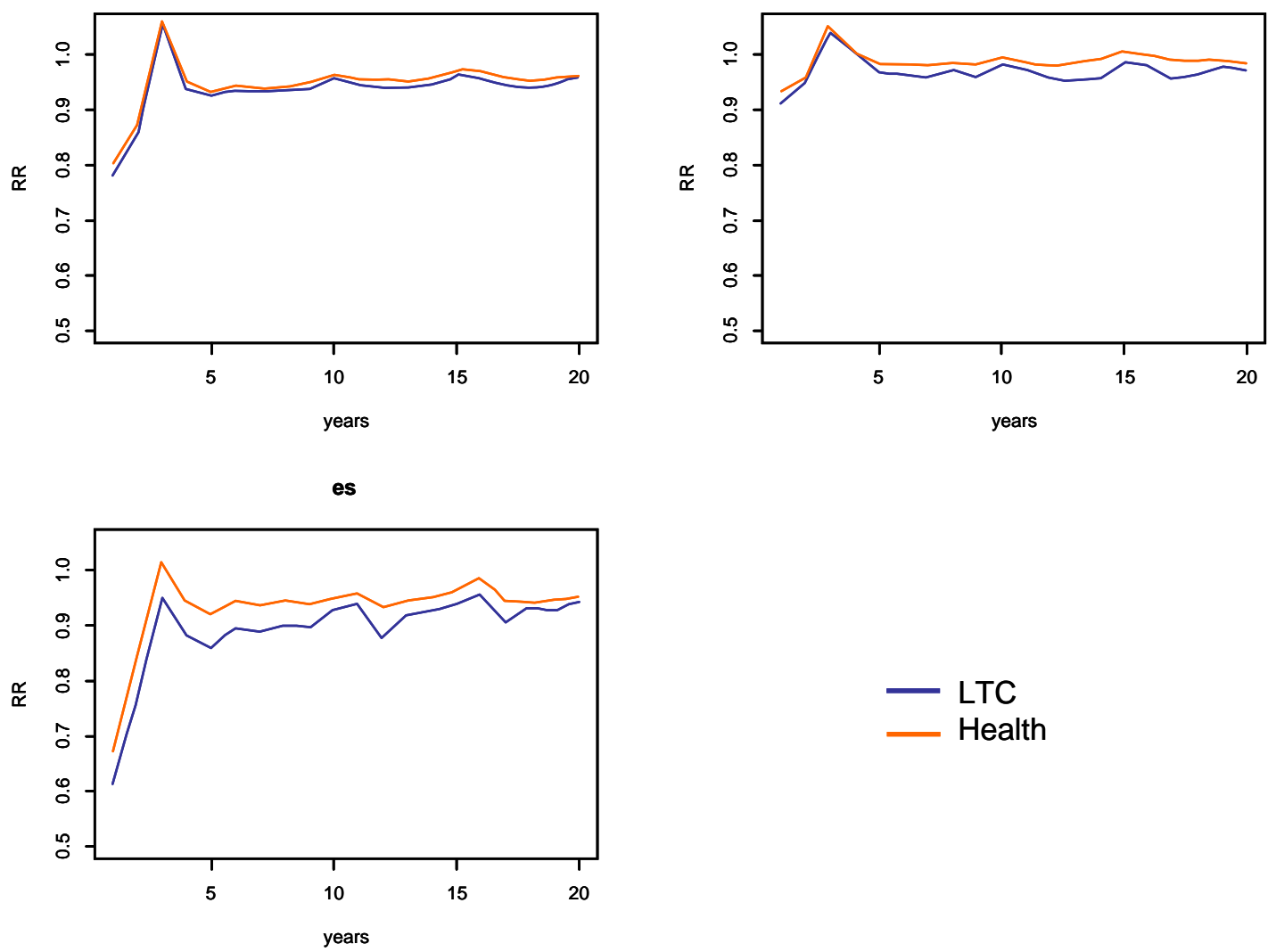

- LTC

Health 
Figures 2 to 4 group countries into five macro geographical regions: Southern, Central, Nordic and Eastern countries. They point again to the regional singularities in the existing health care and LTC services' retention rates. Southern European countries, for example, share relatively lower retention rates' values for LTC occupations. Although Portugal and France show a converging pattern of LTC retention rates toward the health sector levels, differences in the two sectors are striking in the rest of the economies belonging to this group. Moreover, they appear constant over time. These differences appear in some eastern economies as well despite the scarcity of data that threatens proper analyses in these countries.

\section{Figure 2}

One-year retention rates in Southern countries

cy

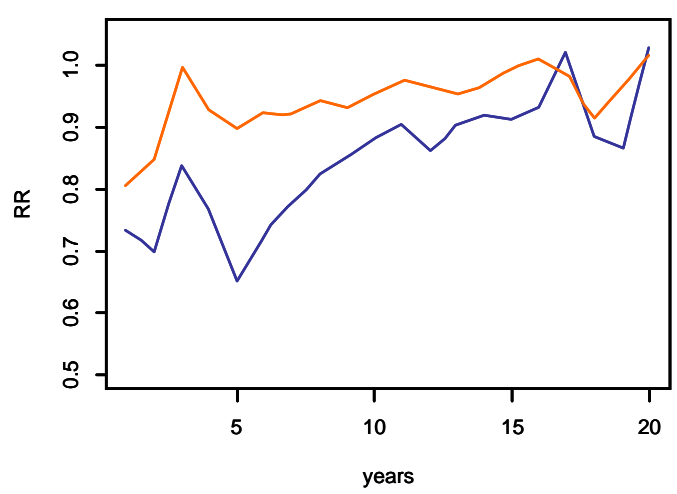

pt

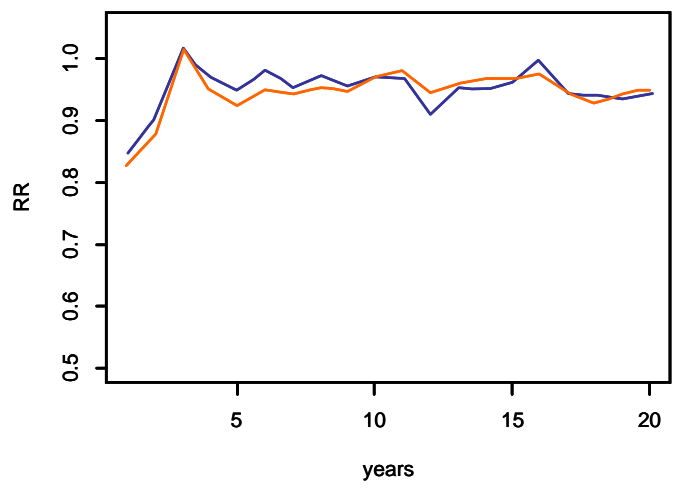

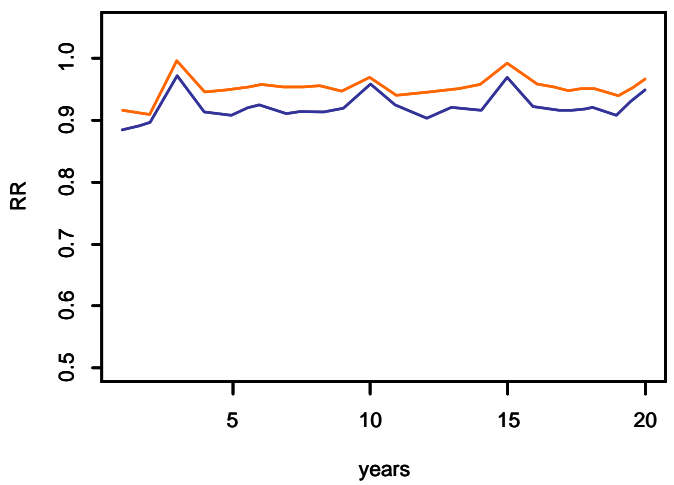
LTC Health

Note: Average one-year retention rates computed for the first 20 years of tenure. Data span for the United Kingdom, France, Italy and Spain: 1992-2010; Germany, 2002-2010. 
Figure 3

One-year retention rates in Central European countries

nl

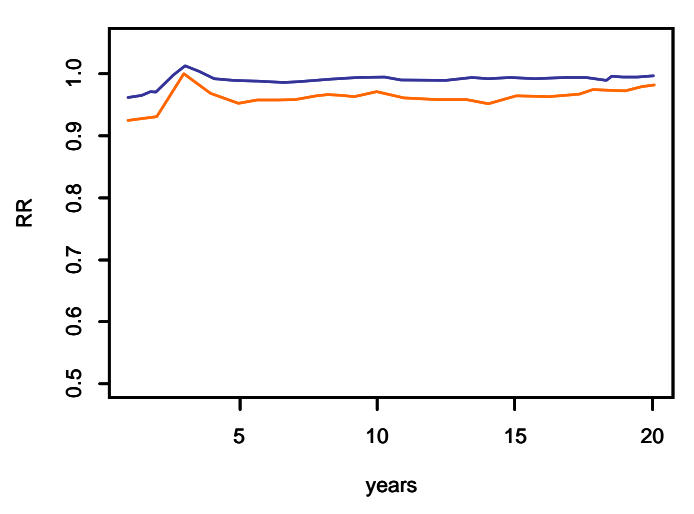

be

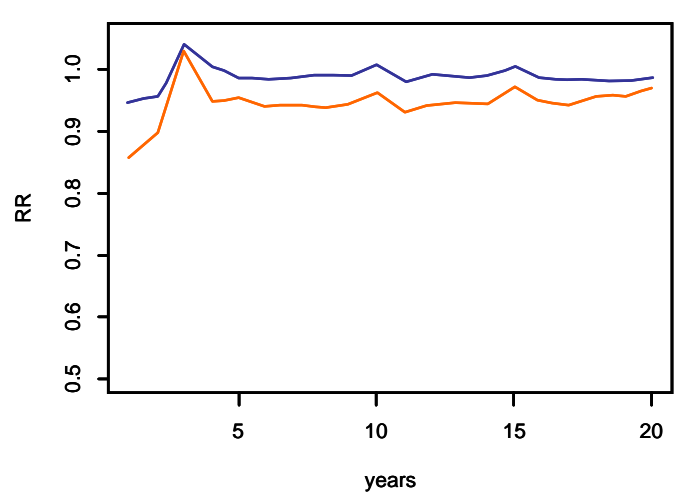

ie

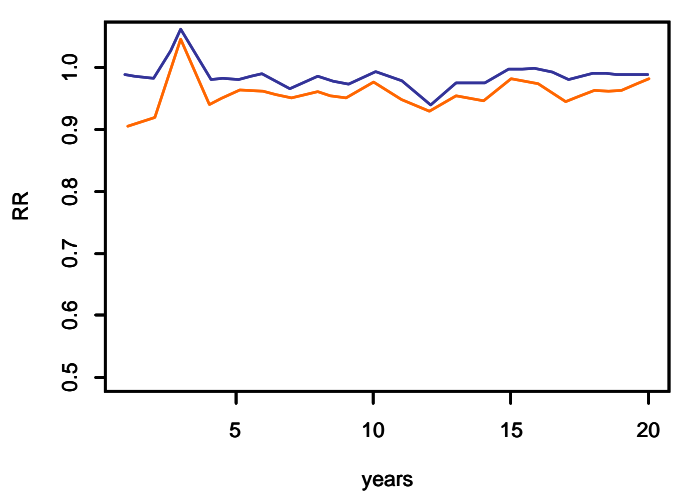

ch

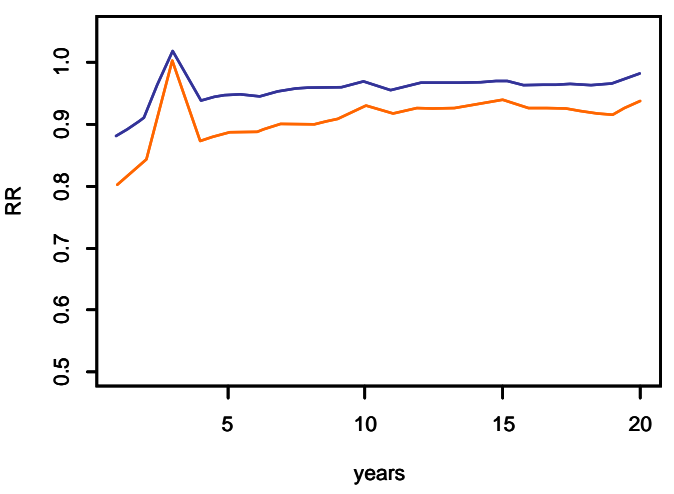

at

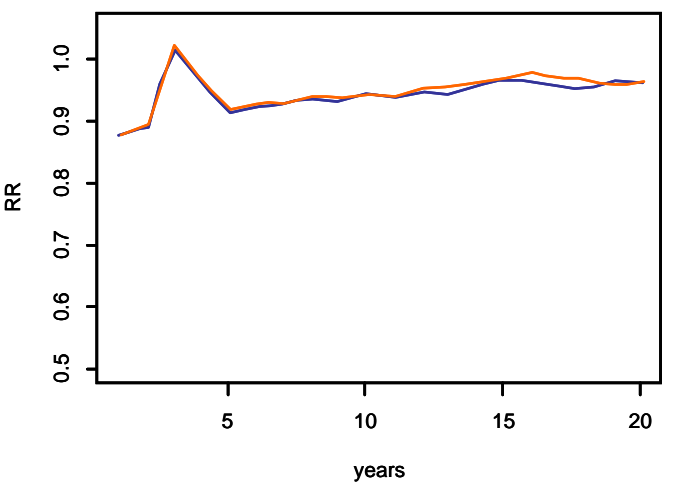

lu

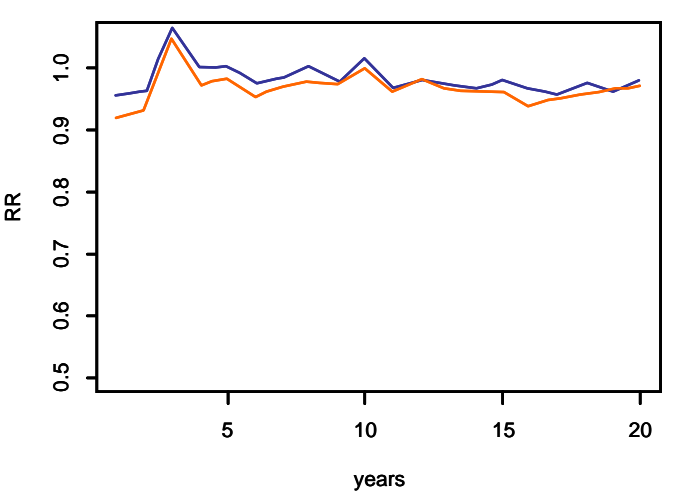

LTC

Health 
Figure 4

One-year retention rates in Nordic countries

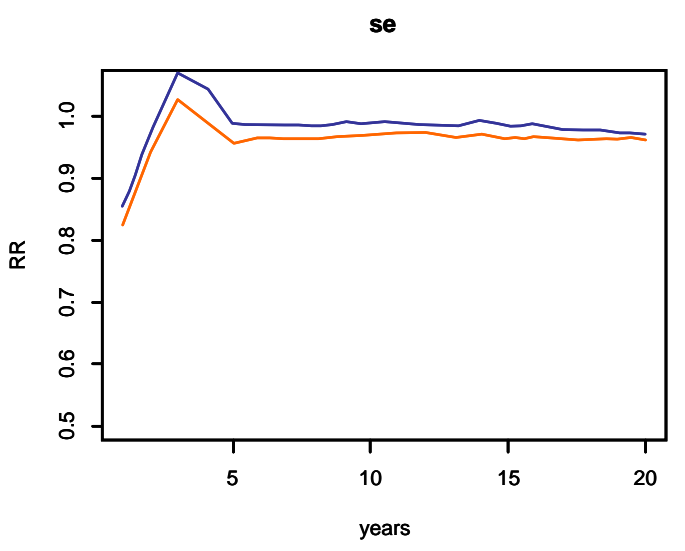

dk

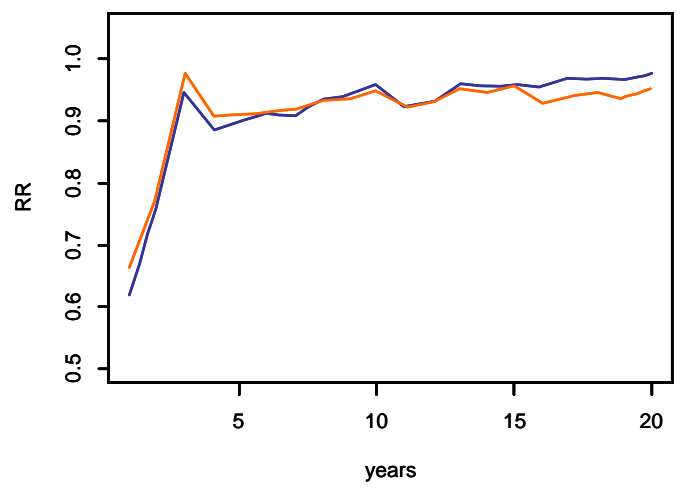

is

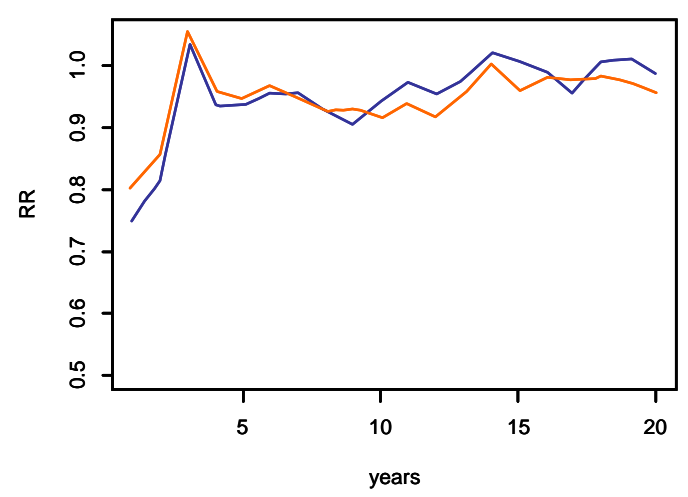

no

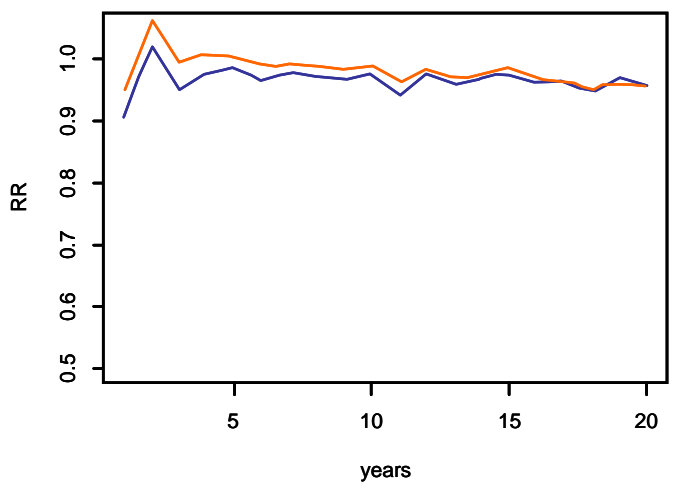

fi

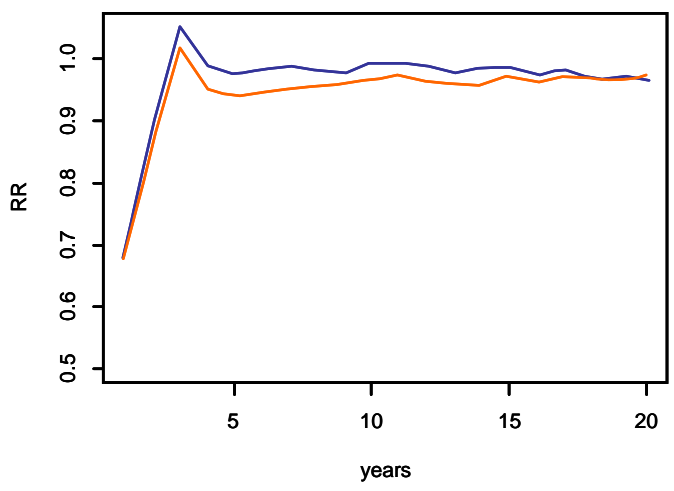

LTC

Health 
Figure 5

One-year retention rates in Eastern European countries

Cz
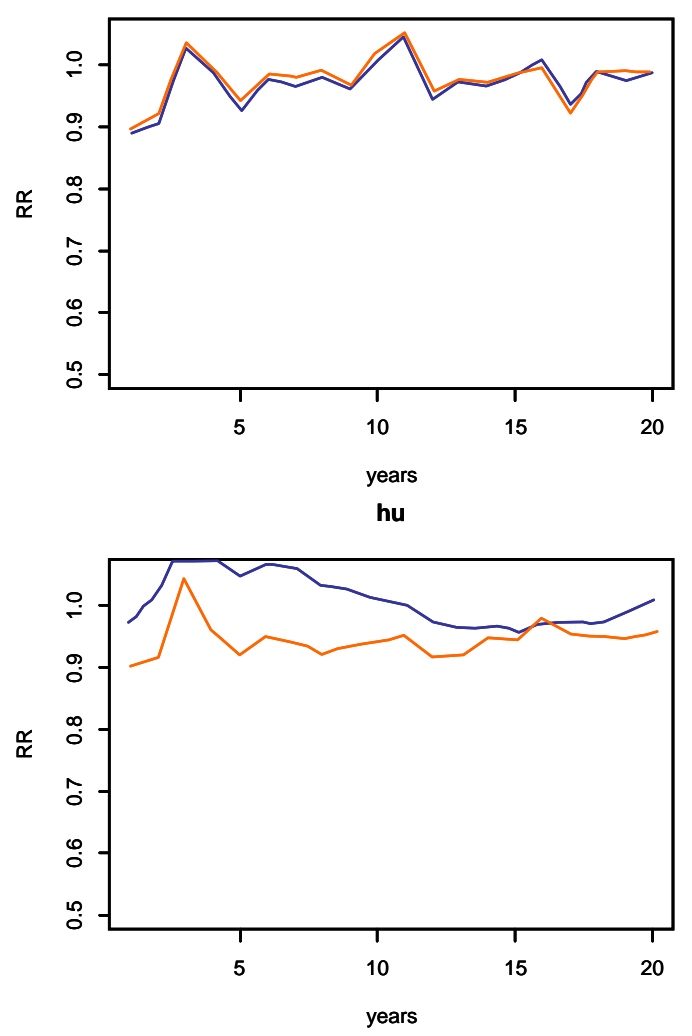

It

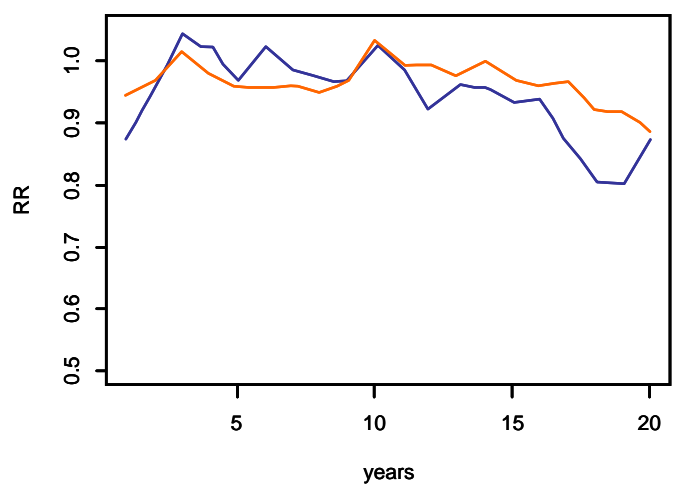

ee

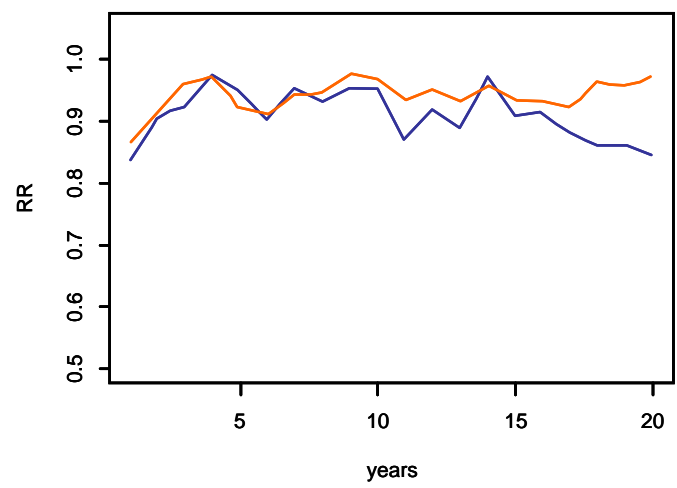

ro
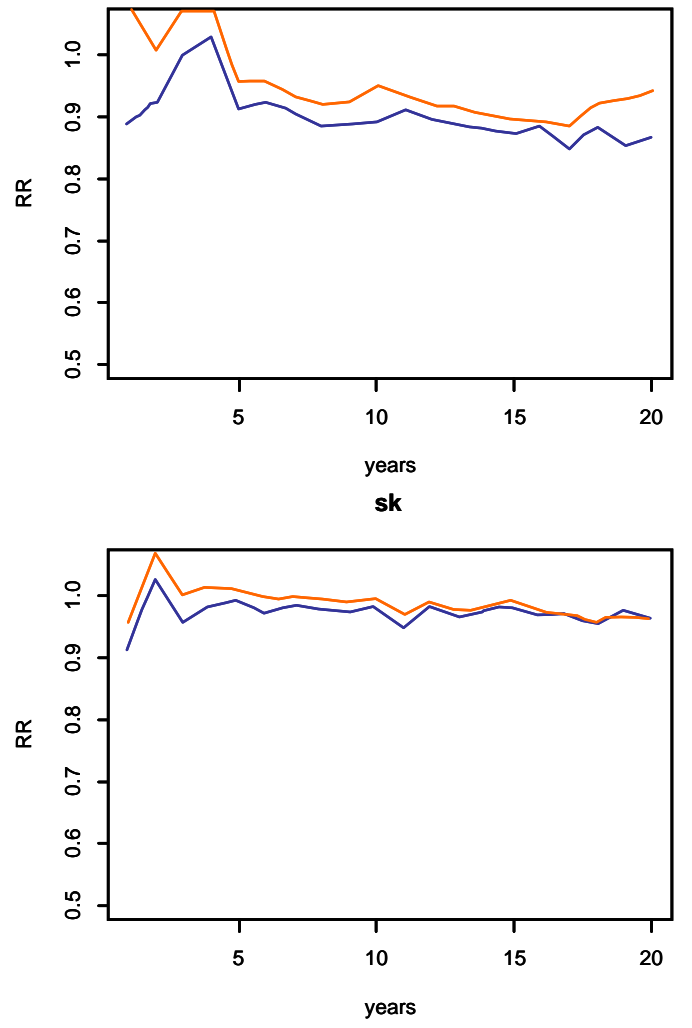

Iv

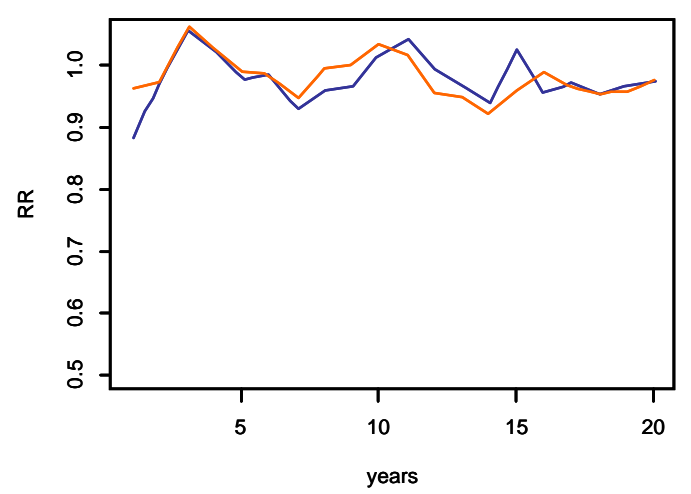


Central European countries present the opposite scenario. In the Netherlands, Switzerland, Belgium and Ireland, LTC workers have higher conditional continuation probabilities than their health sector colleagues. In the United Kingdom, Austria and Luxemburg, the retention rates of LTC services and the health sector move accordingly, meaning that the differences in job attractiveness between the two sectors are lower.

Heterogeneity happens to be characteristic of the Nordic region. In Sweden and Finland, LTC retention rates appear consistently higher. In the rest of the countries composing this geographical cluster, health care and LTC occupations present similar stability indexes.

In Southern and, in some cases, Eastern Europe LTC retention rates are lower than the typical health occupation. Conversely, in Sweden, Finland and most Central European countries, LTC values are higher; in half of the countries observed LTC and health care retention rates are close and move accordingly. This suggest that LTC country (and regional) idiosyncrasies in the service provision sector might matter at country level, advocating for a positive differential in favor of Central European states in terms of attractiveness and therefore job quality.

The performed job-stability analysis based on the estimation of retention rates breaks down European countries into three groups. In the first one, LTC represents less stable, thus less attractive, occupations with a marked and constant difference with respect to the health sector over time. Belonging to this group are most Southern European countries, and some Eastern countries (Romania and some Baltic economies). The second group is composed of all those countries where differences between LTC and health care retention rates are not clear. Large economies, such as the United Kingdom and France are part of this second cluster. The third group is made up of countries where LTC presents higher job stability patterns. In some Central European countries (Germany, Netherlands, Switzerland and Belgium) and some Nordic countries (Sweden and Finland), LTC occupations have higher attractiveness than other healthrelated occupations.

\section{Discussion}

A growing interest in Long-Term Care services exists among policy-makers and service providers (European Commission, 2008 and 2012; OECD, 2011a). Present demographic projections and concerns about financial constraints call attention to this sector's challenges, some of which relate to its workforce's characteristics and potential workforce shortages driven by a supposed low attractiveness of LTC-related occupations. Existing literature in the field suggests that employment opportunities are perceived as unappealing and high turnover rates follow. This, in turn, can negatively affect the quality and the cost of such services.

In order to account for the magnitude of this phenomenon, we applied a widely accepted methodology using European Labour Force Survey data from 1992 to 2011. As far as we know, this is the first within and cross-country comparable measure of actual job stability for this sector. Job stability values for LTC workers were compared with corresponding values for health workers in general in 26 European countries.

Our findings suggest that LTC occupations often appear as attractive as the rest of health related jobs, though this also depends on regional idiosyncrasies. Broadly speaking, countries can be grouped into three large regions: countries where LTC jobs exhibit low retention rates (i.e., are perceived as a low attractive career options), mainly Southern and Eastern European 
states; countries where little difference exists between LTC and other health-related jobs; and countries where LTC jobs show a higher stability (and therefore attractiveness) than other jobs in the health sector, mainly Central European states. These findings suggest the presence of country (and regional) idiosyncrasies that could be at the base of the observed differences. Furthermore, according to the premises of this paper, potential workforce shortages are more likely to occur in southern European countries.

Since LTC services are provided under different systems across Europe, future research needs to focus on how job attractiveness and retention relate to national LTC organization and management. Based on our initial findings, further research should examine various factors that could affect LTC provision and workforce such as worker characteristics (e.g., gender, education, experience and professional status) and job-related characteristics (e.g., firm size, hours and shift configuration), and institutional framework (e.g. job related regulations), all of which could contribute to understand the phenomena studied. The provision system implemented in each country, in terms of, for example, public-private expenditure relations or shares of formal and informal nature in total should also be the focus of research to explain cross-country differences in LTC workforce retention. Once different variables' influence on attractiveness had been disentangled, they could be the object of policy decisions aimed at enhancing career prospects of LTC jobs. The methodology and job stability measures presented here are a first empirical step in this direction. 


\section{References}

Baughman, R. A., and K. E. Smith (2011), "Labor Mobility of the Direct Care Workforce: Implications for the Provision of Long-Term Care," Health Economics 21, pp. 1402-1415.

BLS (2012), "Employment Projections 2010-2020," Bureau of Labour Statistics - News Release USDL-12-0160.

Brochu, P. (2011), "Estimating Labour Market Transitions and Continuations using Repeated Cross Sectional Data," Economics Letters 111:1, pp. 84-87.

Castle, N. G. (2008), "Nursing Home Caregiver Staffing Levels and Quality of Care," Journal of Applied Gerontology 27:4, pp. 375-405.

Castle, N. G., and J. Engberg (2005), "Staff Turnover and Quality of Care in Nursing Homes," Med Care 43:6, p. 616.

Corak, M. R. (1993), "The Duration of Unemployment during Boom and Bust," Statistics Canada, Analytical Studies Branch.

Corak, M., and A. Heisz (1996), "Alternative Measures of the Average Duration of Unemployment," Review of Income Wealth 42:1, pp. 63-74.

Dawson, S. L., and R. Surpin (2000), "The Home Health Aide: Scarce Resource in a Competitive Marketplace," Care Management Journals 2:4, pp. 226-231.

Delp, L., S. P. Wallace, J. Geiger-Brown, and C. Muntaner (2010), “Job Stress and Job Satisfaction: Home Care Workers in a Consumer-Directed Model of Care," Health Services Research 45:4, pp. 922-940.

Diebold, F. X., D. Neumark, and D. Polsky (1997), “Job Stability in the United States,” Journal of Labor Economics, 15:2, pp. 206-233.

European Commission (2009), Employment in Europe 2009, Brussels.

European Commission, Directorate-General for Economic and Financial Affairs (2008), The 2009 Ageing Report: Underlying Assumptions and Projection Methodologies for the EU-27 Member Syayes (2007-2060), Office for Official Publications of the European Communities.

Fujisawa, R., and F. Colombo (2009), "The Long-Term Care Workforce: Overview and Strategies to Adapt Supply to a Growing Demand," OECD Health Working Papers.

Geerts, J. (2011), The Long-Term Care Workforce: Description and Perspectives, Brussels.

Hackmann, T. (2009), “Arbeitsmarkt Pflege: Bestimmung der künftigen altenpflegekräfte unter Berücksichtigung der Berufsverweildauer,” No. 40, Diskussionsbeiträge//Forschungszentrum Generationenverträge der Albert-Ludwigs-Universität Freiburg.

Harrington, C., T. Ng, S. H. Kaye, and R. Newcomer (2009), "Home and Community-Based Services: Public Policies to Improve Access, Costs, and Quality," San Francisco, CA: University of California San Francisco Center for Personal Assistance Services.

Heisz, A. (2005), "The Evolution of Job Stability in Canada: Trends and Comparisons with US Results," Canadian Journal of Economics/Revue canadienne d'economique 38:1, pp. 105-127. 
Hussein, S., J. Manthorpe, and M. Stevens (2010), “People in Places: A Qualitative Exploration of Recruitment Agencies' Perspectives on the Employment of International Social Workers in the United Kingdom,” British Journal of Social Work 40:3, pp. 1000-1016.

Hussein, S., J. Manthorpe, and M. Stevens (2011), "Social Care as First Work Experience in England: A Secondary Analysis of the Profile of a National Sample of Migrant Workers," Health and Social Care in the Community 19.1 (2011): pp. 89-97.

Hussein, S., J. Manthorpe, and M. Stevens (2011), “The Experiences of Migrant Social Work and Social Care Practitioners in the United Kingdom: Findings from an Online Survey," European Journal of Social Work 14.4: pp. 479-496.

Kraus, M., M. Riedel, E. Mot, P. Willem, Gerald Rahrling, and Thomas Czypionka (2010), “A Typology of Long-Term Care Systems in Europe," Centre for European Policy Studies.

Jiménez Matín, S., and C. Villaplana Prieto (2012), "Trade-off between formal and informal care in Spain,” The European Journal of Health Economics 13, pp. 461-490.

Mennicken, R., B. Augurzky, H. Rothgang, and J. Wasem (2013), "Explaining differences in remuneration rates of nursing homes in Germany," The European Journal of Health Economics, pp. 1-10.

Nadash, P., P. Doty, K. J. Mahoney, and M. Schwanenflugel (2012), "European Long-Term Care Programs: Lessons for Community Living Assistance Services and Supports?" Health Services Research, 47:1 pt1, pp. 309-328.

National Clearinghouse on the Direct Care Workforce (2006), Factsheets: Who are Direct Care Workers? Paraprofessional Healthcare Institute.

Neumark, D., D. Polsky, and D. Hansen (1999), "Has Job Stability Declined Yet? New Evidence for the 1990s," Journal of Labor Economics, 17:S4, pp. S29-64.

Ochsner, M., C. Leana, and E. Appelbaum (2009), "Improving Direct Care Work: Integrating Theory, Research and Practice," White Paper - Alfred P. Sloan Foundation.

OECD (2011), Help Wanted?: Providing and Paying for Long-Term Care, C. Francesca, L. N. Ana, M. Jaime, T. Frits, OECD Health Policy Studies, OECD Publications.

OECD (2011), Long-Term Care in Health at a Glance 2011: OECD Indicators. http://dx.doi.org/10.1787/health_glance-2011 - en: OECD Publishing, p. 161.

Olson, S. (2010), The Role of Human Factors in Home Health Care: Workshop Summary, National Academy Proceedings.

Organization for Economic Cooperation and Development OECD (2011), Health at a Glance 2011: OECD Indicators.

Riedel, M., and M. Kraus (2011), "The Organisation of Formal Long-Term Care for the Elderly: Results from the 21 European Country Studies in the ANCIEN Project," Centre for European Policy Studies.

Rodriguez Sampayo, A., B. Alvaréz, and E. Rodríguez Miguez (2011), "Distribución territorial de la dependencia en España y Europa,” Papeles de Economía Española, 129, pp. 27-47. 
Salant, S. W. (1977), "Search Theory and Duration Data: A Theory of Sorts," The Quarterly Journal of Economics 91:1, pp. 39-57.

Seavey, D. (2004), The Cost of Frontline Turnover in Long-Term Care. Washington, DC.: Better Jobs Better Care National Program Office.

Sider, H. (1985), "Unemployment Duration and Incidence: 1968-1982," American Economics Review, 75:3, pp. 461-472.

Simonazzi, A. (2009), "New Skills for New Jobs? Status quo and perspectives for the elderly care sector in Europe," European Employment Observatory (EE0) Thematic Paper. 